\title{
"A turbulência que se aprofunda ao nosso redor"*
}

\author{
Resenha de Capitalismo em debate: uma conversa na \\ teoria crítica, de Nancy Fraser e Rahel Jaeggi (São \\ Paulo, Boitempo, 2020)
}

\author{
José Ivan Rodrigues de Sousa Filho \\ ivanrsfilho@hotmail.com \\ (Universidade Federal de Santa Catarina, Florinópolis, Brasil)
}

DOI: http://dx.doi.org/10.11606/issn.2318-9800.v25i1p121-132

Capitalismo em debate é, acima de tudo, uma obra filosófica sintomática do tempo presente. E o é porque o capitalismo se encontra em discussão na esfera pública, em especial nos Estados Unidos, onde o livro, há dois anos, viera a lume e onde Bernie Sanders, neste ano, conduziu uma pré-candidatura presidencial declaradamente socialista que angariou intenso apoio e provocou acalorado debate. Essa recente problematização política do capitalismo tem lugar sob uma constelação de graves desenvolvimentos econômicos, políticos e culturais que remontam ao ocaso dos anos 2000: a crise financeira mundial de 2007-2009, o imediato resgate estatal de graúdos bancos privados à beira da falência, o consequente agravamento da crise das finanças públicas, a política de austeridade fiscal então renovadamente receitada e imposta, o duradouro refreamento do crescimento econômico, os protestos massivos que proliferaram por todo o mundo em indignada reação a esse plexo de crises econômicas, os movimentos políticos regressivos que também emergiram mundo afora, as políticas públicas econômicas e culturais promovidas por novos governos de extrema-direita hiper-reacionária que se instalaram com o apoio de tais movimentos e que tanto mantêm como aprofundam a mesma diretriz neoliberal de distribuição regressiva da riqueza social pela qual se nortearam prévios governos de centrodireita e centro-esquerda, além de intensificarem o escangalhamento do Estado de bem-estar social, denegarem as profundas mudanças socioeconômicas necessárias para evitarmos ou enfrentarmos a iminente crise ecológica global, insuflarem o

\footnotetext{
* Trata-se de uma citação da obra resenhada, situada na página 9.
} 
etnonacionalismo e o racismo, reforçarem o machismo e a homofobia e minarem o Estado de direito e a democracia liberal. É sob a opaca radiação dessa constelação capitalista que se gesta o livro de Nancy Fraser e Rahel Jaeggi, e é a tal constelação que ele responde diretamente, sintomatizando o nosso tempo em três sentidos: ele reflete (sobre) um complexo temático discutido publicamente, um complexo de crises distintas e interligadas de alcance global e um complexo heterogêneo de movimentos e lutas sociais.

Vertida para o nosso português por Nathalie Bressiani, filósofa notoriamente versada nas teorias críticas das duas autoras, a obra se torna muito mais acessível no Brasil, onde tanto Fraser como Jaeggi, embora sejam filósofas preeminentes com diversas obras de imenso peso teórico, ainda são pouco traduzidas: justamente as mais importantes obras de ambas (por exemplo: de Fraser, Fortunes of feminism: from state-managed capitalism to neoliberal crisis; de Jaeggi, Kritik von Lebensformen) ainda não o foram. Também nesse sentido, Capitalismo em debate é uma novidade muitíssimo bem-vinda: pela precisão e pela consistência teórica do trabalho de tradução e por difundir entre nós o que mais recentemente teorizaram a filósofa estadunidense e a suíça.

É na tentativa de fazer jus à obra (bem como à sua tradução brasileira) que, a seguir, se elabora um panorama interpretativo dela, e se esboçam algumas observações críticas gerais.

\section{À guisa de conversa}

O que mais dá nas vistas quando se abre, pela primeira vez, o livro de Fraser e Jaeggi e até provoca um leve estranhamento durante os primeiros progressos da leitura é a peculiar forma discursiva em que o livro se apresenta. Trata-se mesmo de uma "conversa", conforme advertido pelas autoras já no subtítulo do livro. Mas se trata de uma conversa apenas entre aspas, pois o debate entre elas não se configura, de fato, como uma conversa propriamente dita: falada e espontânea, informal e cotidiana.

Trata-se, antes, de uma conversa escrita (não só transcrita): e escrita com a intenção de constituir um livro, não um livro qualquer, mas um livro plenamente teórico, um livro de teorização crítica da sociedade capitalista. Uma conversa, portanto, minuciosamente organizada em quatro aspectos básicos. Em primeiro lugar, ela põe em foco uma temática ampla e complexa, mas bem demarcada e sistematicamente abordada, abarcando o capitalismo, a própria teorização crítica do capitalismo e, ademais, a práxis política anticapitalista. Em segundo lugar, o livro se desenrola num nível de profundidade teórica deliberadamente restringido, ainda que elevado, pois, mesmo que pretenda ser plenamente teórico, não pretende 
esgotar a teorização que empreende, nem aprofundá-la tanto que se torne acessível exclusivamente a acadêmicos familiarizados com esse tipo de teorização, inacessível, porém, para grande parte do público potencial. Em terceiro lugar, a "conversa" se caracteriza por uma intencional e constante moderação do seu nível de polemização, considerando que as duas autoras ostentam e mantêm entre si muitas divergências fortes, inclusive divergências de saída (dentre as quais se destaca a divergência quanto a conceber o capitalismo como ordem social institucionalizada, como defende Fraser, ou como forma de vida, como defende Jaeggi ${ }^{1}$ ), mas não querem travar a "conversa", nem a espichar exageradamente, nem a tornar árida com a multiplicação de ressalvas, objeções e encruzilhadas teóricas. E, em quarto lugar, o livro apresenta uma exposição cujo desenvolvimento é articulado em quatro grandes blocos, ou capítulos, bem delimitados e estreitamente justapostos na seguinte sequência: conceituação - historicização - crítica teórica - contestação política (sempre do capitalismo).

Intentando constituir um livro teórico e organizadíssima nos seus aspectos básicos, a "conversa" se faz, então, altamente formal e inteiramente acadêmica. Por isso, o seu público potencial é formado, sobretudo, por acadêmicos, intelectuais e outros leitores excepcionais, mas não só pelos que já têm alguma intimidade com a teorização crítica do capitalismo. Não se trata, em todo caso, de obra dirigida prioritariamente a "leigos": inclusive nesse aspecto, a ligação da teoria com a práxis não é, aqui, concebida como imediata; há certo hiato entre o terceiro e o quarto capítulo, entre a crítica teórica e a contestação política, hiato que não é intransponível, mas não pode ser suprimido nem ignorado, de modo que os destinatários preferenciais de Capitalismo em debate são os que transitam em palcos e plateias de debates teóricos.

\section{Retomada de produções acadêmicas individuais anteriores}

A maior parte da obra reapresenta, de maneira resumida, mas consideravelmente detalhada, os principais conceitos, explicações, teses e

\footnotetext{
1 Há outras três divergências centrais entre as autoras, a saber: primeiro, ao passo que Jaeggi parece manter uma considerável abertura para uma teoria da modernidade, ainda que não desenvolva uma, Fraser parece ater-se completamente à teorização do capitalismo, sem preocupar-se em caracterizálo como formação social moderna e em distingui-lo de formações sociais pré-modernas. Segundo, enquanto Jaeggi abraça uma crítica ética do capitalismo que, malgrado formal, é enfática, já que focada na alienação, Fraser assume uma crítica ética do capitalismo que é bastante tímida e parece ser mais política que ética, já que enfoca a autodeterminação coletiva quanto às mais importantes questões econômicas. Terceiro, se Fraser não hesita em conceber os movimentos sociais hodiernos, inclusive os regressivos, como reações diferentes ao neoliberalismo hegemônico, Jaeggi reluta em aceitar tal concepção e não descarta hipóteses que explicam os movimentos sociais regressivos por prismas predominantemente simbólicos, realçando, por exemplo, o racismo inveterado, a misoginia visceral, a homofobia entranhada e o ressentimento social que os impulsionaria.
} 
pressuposições de ambas as produções acadêmicas. Assim, quem ainda não travou contato com o que Fraser e Jaeggi, cada uma individualmente, já haviam publicado relativamente à crítica do capitalismo encontra, em Capitalismo em debate, um acesso adequado, amplo e instigante à particular crítica do capitalismo de cada uma das autoras.

No entanto, a obra não se circunscreve a uma reapresentação do já apresentado por cada uma delas alhures. Capitalismo em debate mescla a essa reapresentação, aqui e acolá e até em abundância, novos aprofundamentos, desdobramentos e esclarecimentos teóricos. Justamente a forma de "conversa" que tem a obra possibilita e convida a isso: cada uma das duas interlocutoras, recorrentemente, pressiona a outra a mais bem elaborar alguns aspectos da sua própria crítica do capitalismo, o que conduz, então, a alguns ganhos teóricos de reflexividade, abrangência e clareza. ${ }^{2}$ Há, ainda, inovações teóricas na obra em relação ao que as autoras haviam teorizado até então. ${ }^{3}$ Assim, proporciona-se, a quem já havia travado contato com a crítica do capitalismo de Fraser e/ou com a de Jaeggi, a possibilidade de retomar as suas leituras anteriores, levantar novamente questões que essas leituras the suscitaram e colocá-las perante a nova obra, tentando encontrar na última respostas para as primeiras, ainda que, nesse movimento, possa, com muita probabilidade, confrontarse com uma segunda onda de questões.

Outra vantagem da forma de "conversa" da obra é que se produz permanentemente a possibilidade de diversas comparações entre as duas críticas. Podem-se comparar os conceitos-chave empregados por cada uma das autoras. Podemse comparar as explicações fundamentais que cada uma delas dá sobre: ontologia social do capitalismo; desenvolvimento temporal e diversificação espacial do capitalismo;

\footnotetext{
2 Por exemplo, quanto à conceituação do capitalismo, Fraser aprofunda reflexivamente a sua própria concepção ao explicitar que ela emprega duas metodologias distintas e que, no entanto, não correspondem a duas, mas a uma única ontologia social, ainda que diversificada para dar conta das diversas esferas sociais em que se divide estruturalmente a sociedade capitalista. Trata-se de uma metodologia estrutural-institucional e de uma metodologia de teoria da ação. Já quanto à historicização do capitalismo, Fraser desdobra a sua concepção, tornando-a mais abrangente, ao apontar um novo regime de acumulação capitalista, vigente do século XVI ao XVIII, anterior ao capitalismo liberal e concorrencial do século XIX, a saber, o capitalismo mercantil. Ademais, Fraser clarifica, quanto à conceituação do capitalismo, que a sua concepção não é meramente funcionalista, mas é também normativa; além do mais, clarifica, quanto à historicização do capitalismo, que o ideal seria elaborá-la de modo conjunto e sistemático, mostrando como as relações profundamente instáveis que a economia capitalista, de um lado, mantém com o poder público, a reprodução social e a natureza não humana, de outro, desenvolvem-se, ao mesmo tempo, distinta e combinadamente.

3 Por exemplo, em relação à crítica teórica do capitalismo, Fraser inova ao afirmar que a sua crítica do capitalismo tem não só uma dimensão funcionalista (focada em contradições estruturais e tendências de crise) e uma dimensão moral (focada em dominações institucionalizadas de classe, gênero e raça), mas também uma dimensão ético-estrutural que diz respeito à falta de autodeterminação coletiva no que se refere a questões econômicas centrais que moldam profundamente a forma de vida abrangente, sobretudo a questão do controle e do emprego do excedente social. $\mathrm{E}$, em relação à contestação política do capitalismo, Fraser também inova ao afirmar que há uma crise de legitimação em curso, uma crise da hegemonia (do senso comum político) neoliberal, sendo que, em artigo publicado três anos antes, afirmara que faltava precisamente tal crise de legitimação.
} 
distinção e articulação das dimensões específicas de uma crítica abrangente do capitalismo; análise das lutas sociais anticapitalistas hodiernas. Podem-se comparar, ainda, as teses centrais que cada uma delas articula quando se põem a explorar os terrenos da teoria social, da economia política, da metacrítica social e da análise empírica. E se podem comparar as mais importantes pressuposições subjacentes a cada uma das duas críticas do capitalismo, pressuposições metodicamente trazidas à tona e bastante discutidas em Capitalismo em debate. Além da diversidade do que pode ser submetido à comparação, também são diversos os critérios que podem ser utilizados para comparar: pode-se comparar à luz, por exemplo, dos critérios de fecundidade teórica, capacidade elucidativa, agudeza crítica e conectividade com a práxis política atual. Aliás, as próprias autoras usam, com frequência, os mencionados critérios para exigirem, uma da outra, respostas satisfatórias a várias questões abordadas no livro.

Retomando as suas próprias produções acadêmicas, Fraser e Jaeggi procedem, além do mais, a uma relativa sistematização das suas críticas do capitalismo, as quais se encontravam, até então, dispersas numa vasta lista de artigos e livros. E isso diz respeito principalmente a Fraser, que tem uma carreira acadêmica mais extensa e mais numerosas publicações que Jaeggi e, além disso, está mergulhada, já há uns bons dez anos, num processo de elaboração de uma nova crítica do capitalismo, publicando os seus resultados parciais de modo intermitente e numa prolífica sequência cumulativa, o que thes impõe o aspecto de partes formadoras de um complexo mosaico ainda inconcluso. Trata-se de uma crítica do capitalismo nova, inclusive, em relação àquela que a mesma Fraser, até então, elaborara ${ }^{4}$ e que não era, como a de agora, centrada: (a) nas divisões institucionais axiais que estruturam a sociedade capitalista em diversas esferas funcional, ontológica e normativamente específicas, mas interdependentes; (b) nas várias tendências de crise do capitalismo produzidas pelas incompatibilidades fundamentais e irredutíveis da lógica própria da economia capitalista, de um lado, com as lógicas próprias do poder público, da reprodução social e da natureza não humana, de outro; (c) nas lutas sociais travadas nas fronteiras entre a economia capitalista e os seus imprescindíveis planos de fundo político, sociorreprodutivo e natural. Esse ambicioso projeto teórico de Fraser, no entanto, não havia sido, até agora, realizado de modo concentrado (num grande livro) e rigorosamente sistemático, mas numa comprida fieira de artigos distribuídos entre diferentes revistas e livros, ${ }^{5}$ de maneira que, em razão da própria forma artigo, ela não havia conseguido, até agora, conferir à sua nova crítica do capitalismo uma exposição completa e unificada.

4 As obras mais emblemáticas da fase anterior da crítica do capitalismo de Fraser são: Fraser \& Honneth (2003) e Fraser (2013).

5 Ver, por exemplo, os seguintes artigos: Fraser (2014), Fraser (2018a), Fraser (2016), Fraser (2018b), Fraser (2018c), Fraser (2020). 
Apesar do seu currículo acadêmico menos volumoso, também Jaeggi se caracteriza pela mesma dispersão da sua interlocutora - uma dispersão, vale notar, nem errática, nem inconsciente, nem insuscetível à síntese. De fato, também Jaeggi elaborou a sua crítica do capitalismo de modo fragmentário. Num primeiro livro, ela elaborou o seu critério ético para a crítica do capitalismo, a saber, a alienação. Depois, num artigo, elaborou o arcabouço conceitual e explicativo da sua crítica da ideologia. Noutro artigo, veio a elaborar a sua metacrítica, que propõe uma teorização do capitalismo que indissoluvelmente entremeie análise e crítica e seja, ao mesmo tempo, funcional e ética. Elaborou, num terceiro artigo, um conceito funcional e ético de trabalho. Em seguida, noutro livro, elaborou a sua teoria social, centrada nas formas de vida. Elaborou, ainda, num quarto artigo, um conceito amplo de economia, economia como conjunto de práticas sociais específicas, mas inseparavelmente atreladas a outros tipos de práticas sociais e, enquanto conjunto, completamente partes, fundamentalmente características e parcialmente constitutivas de uma forma de vida específica; e assim por diante. ${ }^{6}$ Portanto, também à crítica do capitalismo de Jaeggi, faltava uma exposição completa e unificada.

Isso ocasionava, para o público leitor, uma expressiva dificuldade para compreender, de modo sistemático, ambas as críticas do capitalismo, já que elas mesmas foram elaboradas pelas suas autoras de maneira paulatina e fragmentária (mas não incoerente). Capitalismo em debate, não obstante, concede a ambas uma significativa chance de se fazerem sistemáticas enquanto teóricas críticas do capitalismo. Essa chance, contudo, é limitada, pois a sistematização não pode, nesse tipo de livro, escrito à guisa de conversa, ser exaustiva, nem definitiva, no que tange a aprofundamento, desdobramento e clarificação do previamente publicado. A sistematização alcançada é, nesse sentido, relativa: trata-se de alinhavar o já publicado, recuperando explicitamente a sua coerência interna, indo, de vez em quando, um pouco além do já escrito anteriormente, sempre na medida do permitido pela forma "conversa".

\section{O pronunciado protagonismo de Fraser}

A chance de sistematizar as suas dispersas contribuições anteriores para a crítica do capitalismo foi, de fato, aproveitada pelas duas autoras, mas Fraser, visivelmente, a aproveitou muitíssimo mais que Jaeggi. Talvez haja uma razão genética, editorial, para isso: o livro fora encomendado pelo editor estadunidense, ao que tudo indica, como uma homenagem à longeva, profícua e influente carreira acadêmica de Fraser, por ocasião do seu septuagésimo aniversário, em 2017. Ainda que as autoras tenham decidido alterar o propósito do livro proposto pelo editor,

6 Ver Jaeggi (2014), Jaeggi (2008), Jaeggi (2015), Jaeggi (2018a), Jaeggi (2018b), Jaeggi (2017). 
dedicando-o, então, ao estágio atual das suas pesquisas, cujo foco é justamente o capitalismo, é nítido que Jaeggi desempenha, predominantemente, o papel de uma entrevistadora, embora saia uma entrevistadora bastante erudita, perspicaz e crítica. Mesmo quando seria esperado que fosse dela a fala principal, o impulso do protagonismo de Fraser, rapidamente, desponta, se imiscui e se instala.

Nos capítulos I e II, que versam, respectivamente, sobre a conceituação e a historicização do capitalismo, o palco é quase unicamente de Fraser. Jaeggi se restringe, quase completamente, a estimular a sua interlocutora a reapresentar (e, aqui e ali, aprofundar, desenvolver e clarificar) duas grandes propostas suas (da própria Fraser): (a) a proposta de conceituação do capitalismo como uma ordem social cuja especificidade histórica reside na institucionalização de uma esfera econômica que é separada das esferas da reprodução social, do poder público e da natureza não humana, mas que é, ao mesmo tempo, dependente dessas três esferas "não econômicas", ainda que denegue a imprescindível importância econômica que elas possuem e ainda que denegue a parasitação, o esgotamento e a devastação que impõe a elas; (b) a proposta de historicização do capitalismo como uma sequência (retrospectivamente reconstruível como sendo direcional) de regimes de acumulação privada de capital que não se circunscrevem à esfera econômica, mas são, ao mesmo tempo, regimes sociorreprodutivos, políticos, socioecológicos e racializadores, quer dizer, os regimes de acumulação mercantil, liberal, administrado pelo Estado e financeirizado/neoliberal também abrangem, como componentes "não econômicos" essenciais, mas mantidos no plano de fundo, formas específicas de feminilização do “cuidado" e de seguridade social, formas específicas de configuração das relações entre os poderes privados econômicos e os poderes públicos políticos (nacionais e transnacionais), formas específicas de "natureza histórica" e formas específicas de subjetivação/sujeição política e de expropriação econômica.

Já o capítulo III seria, supostamente, o capítulo em que Jaeggi tomaria o protagonismo na "conversa", já que se trata de um capítulo dedicado à metacrítica do capitalismo, ou seja, à reflexão sobre os critérios fundamentais com base nos quais se critica o capitalismo e sobre os tipos gerais de crítica do capitalismo. Enquanto Fraser, até então, na sua produção acadêmica anterior, havia se abstido largamente de escrever sobre a crítica do capitalismo, tendo se concentrado em escrever diretamente sobre o próprio objeto da crítica do capitalismo, é de Jaeggi, possivelmente, a principal elaboração da Teoria Crítica recente em termos de metacrítica do capitalismo. Seria, pois, esperado que, nesse capítulo, a voz preponderante fosse a de Jaeggi. Jaeggi chega a retomar a sua metacrítica do capitalismo já no início do capítulo, definindo, assim, os termos da discussão, de modo que a discussão passa, então, a girar em torno de três tipos gerais de crítica do capitalismo, distinguidos uns dos outros pela adoção de um de três critérios fundamentais: a crítica funcional põe em foco as 
tendências de crise do capitalismo; a crítica moral, a exploração e/ou a injustiça impostas pelo capitalismo; e a crítica ética, a alienação que o capitalismo produz. Definidos desse modo os termos da discussão, Fraser passa, no entanto, a fazer preponderar a sua voz. Primeiro, Fraser concorda com Jaeggi em que não é possível uma crítica puramente funcional do capitalismo, em que toda crítica funcional está ligada, explícita ou implicitamente, a algum ponto de vista normativo e, portanto, a algum tipo de crítica moral e/ou ética, ainda que o desenvolvimento teórico da crítica propriamente normativa se apresente como tímido e fugaz. A partir daí, no entanto, começam a mostrar-se divergências e diferenças entre as duas autoras. Por exemplo, Jaeggi defende que Marx não procedeu a uma crítica diretamente moral do capitalismo, mas Fraser sustenta que há, em Marx, uma dimensão moral explícita, relacionada à justiça política, ou a uma injusta (pois classista) destinação institucionalizada do excedente social. A obstinada oposição que Jaeggi faz a uma crítica moral é, então, contrastada com a insistência de Fraser numa crítica moral centrada nas dominações estruturais não só de classe, mas também de gênero e raça. Além disso (e muito mais importante), Fraser passa a apresentar a sua própria concepção de crítica ética do capitalismo, contrapondo-a abertamente à particular concepção de Jaeggi. E isso leva Fraser a retomar tanto a sua própria conceituação como a sua própria historicização do capitalismo, já desenvolvidas nos dois capítulos anteriores, para salientar-lhes as nuanças propriamente éticas.

Não obstante, é no capítulo III, sem dúvida, que Jaeggi é mais bem-sucedida em expor a sua própria crítica do capitalismo, ao menos nos seus traços gerais: uma crítica baseada em dois critérios entrelaçados, o critério funcional das contradições imanentes e tendências objetivas de crise e o critério ético não essencialista e não substantivo, mas antes processual e formal, da alienação - alienação como obstáculo à liberdade social. Trata-se de uma crítica que, em última análise, põe em relevo a irracionalidade inerente ao capitalismo como uma ordem social que sistematicamente bloqueia experiências sociais e processos de aprendizagem e, assim, distorce profundamente as reações sociais às suas próprias crises, o que acaba por causar e proliferar relações sociais alienadas e fenômenos de estranhamento. Nessa medida, o capítulo III é o capítulo de Jaeggi, ainda que, nele, o desempenho discursivo de Fraser não fique atrás do da sua interlocutora.

No capítulo IV, Fraser reassume mais enfaticamente o seu protagonismo no livro. Isso ocorre porque a crítica do capitalismo de Fraser dispõe de uma elaboração acerca das lutas sociais que é muito mais rica e clarificadora do que a de Jaeggi. Essa elaboração se desenvolve em três vertentes diferentes e, não obstante, interligadas. A primeira vertente é a da ressignificação e ampliação do conceito clássico de "lutas de classe" através do conceito novo de "lutas de fronteira" - o que representa uma contribuição original de Fraser para a renovação do marxismo e da Teoria Crítica. Na 
segunda vertente, Fraser realiza uma apropriação crítica do conceito de "movimento duplo" de Karl Polanyi que o transforma num "movimento triplo", constituído de três amplas tendências de desenvolvimento que atravessam toda a história do capitalismo e se relacionam umas com as outras de maneiras diferentes ao longo dessa história, a saber, as tendências de mercadorização, proteção social e emancipação. Já na terceira vertente, Fraser elabora o diagnóstico acerca do "neoliberalismo progressista" como a corrente política neoliberal hegemônica até há pouco, bem como acerca do recente arruinamento da hegemonia neoliberal sob a pressão geral de movimentos regressivos e emancipatórios, os primeiros alimentando o "populismo reacionário" de extrema-direita, os últimos nutrindo o "populismo progressista" de uma esquerda da qual se espera que possa unir toda a classe trabalhadora em sentido amplo, abarcando todos os expropriados e explorados num bloco contra-hegemônico que vise a uma transformação estrutural da ordem social capitalista. Jaeggi levanta importantes discordâncias e ressalvas a essa tripla elaboração de Fraser. Por exemplo, ela parece adotar uma compreensão mais aguda e mais dramática do racismo, do sexismo e da homofobia que caracterizam os atuais movimentos regressivos e os seus porta-vozes partidários de extrema-direita, em contraposição à proposta de Fraser de compreender essas gravíssimas atitudes sociopolíticas como reações reacionárias à crise da hegemonia neoliberal, suscetíveis, em princípio, ao esclarecimento e à mudança. Além disso, Jaeggi ressalta a necessidade de uma crítica da ideologia hoje, em contraposição à proposta de Fraser de recuperar o conceito de "hegemonia" de Antonio Gramsci. Em todo caso, nesse capítulo final, Jaeggi acaba por restringir-se a comentar as vastas propostas de Fraser.

\section{Uma explicação do predomínio discursivo de Fraser}

É possível explicar, com uma combinação de razões filosóficas e razões relativas à peculiar forma discursiva de Capitalismo em debate, a precedência que a crítica do capitalismo de Fraser exerce continuadamente sobre a de Jaeggi ao longo do livro. Ao conceituar o capitalismo como uma ordem social institucionalizada, Fraser monta um quadro conceitual que the rende algumas expressivas vantagens em relação a Jaeggi. Em primeiro lugar, o quadro conceitual de Fraser é consideravelmente menos abstrato que o de Jaeggi, o qual tem como cerne os conceitos de forma de vida, prática social, problema e processo de aprendizagem. Em segundo lugar, o quadro conceitual de Fraser é não só aberto à historicização - o de Jaeggi também o é -, mas também inerentemente dependente dela, ou seja, somente pode ser desdobrado teoricamente (e, assim, elucidar o seu próprio objeto) mediante uma narrativa abrangente do desenvolvimento histórico do capitalismo - o que não ocorre com o quadro conceitual de Jaeggi, cujo desdobramento teórico é significativamente 
independente de narrativas históricas, precisamente porque é de uma abstração elevadíssima. Em terceiro lugar, o quadro conceitual de Fraser tem como critérios da crítica a estabilidade estrutural (ou a sustentabilidade funcional), a não dominação de classe, gênero e raça e a autodeterminação coletiva socioeconômica, critérios com os quais Fraser consegue criticar o capitalismo de modo, ao mesmo tempo, mais simples, mais fértil e mais convincente do que Jaeggi com os seus critérios de êxito na compreensão e resolução de problemas e não alienação (ou apropriação). E, em quarto lugar, o quadro conceitual de Fraser é capaz de esclarecer imanentemente as lutas sociais de outrora e de hoje de modo abrangente e nuançado, quer dizer, oferece um panorama sistemático delas ao longo de toda a história capitalista, tanto no centro como na periferia do capitalismo mundial e em cada um dos períodos específicos dessa história; e oferece, ainda, um discernimento criterioso daquelas lutas conforme se posicionem em relação à mercantilização da sociedade, à proteção da sociedade contra a mercantilização e à emancipação de grupos sociais que permanecem estruturalmente dominados na sociedade capitalista.

Justamente em virtude dessas características do seu quadro conceitual, a crítica do capitalismo de Fraser se sobressai à de Jaeggi na "conversa". Efetivamente, numa conversa (ainda que seja uma conversa só entre aspas), tende a perder espaço quem discursa muito abstratamente: discursos muito abstratos são mais adequadamente desdobrados em formas de escrever não dialógicas nem inclinadas à altercação oral, quer dizer, em formas de escrever mais monográficas, ensaísticas ou tratadísticas. Nesse sentido, é razoável supor que o quadro conceitual menos abstrato de Fraser tenda a ser propício ao desdobramento do seu particular discurso em Capitalismo em debate, enquanto o quadro conceitual muito mais abstrato de Jaeggi tenda ao contrário. Mesmo no capítulo I e no III, os mais abstratos do livro, a menor abstração do quadro conceitual de Fraser lhe proporciona bastante espaço discursivo. Além disso, as temáticas às quais se dedicam os dois outros capítulos do livro são francamente favoráveis a Fraser: no capítulo II e no IV, dedicados, respectivamente, à história do capitalismo e às lutas anticapitalistas atuais, é quase óbvio que Fraser se destaque muito mais que Jaeggi, dado que, entre as duas, é apenas Fraser que oferece uma crítica do capitalismo eminentemente histórica e explícita e sistematicamente ligada à práxis política anticapitalista.

\section{Estamos conversados?}

A forma de "conversa" que as autoras deram ao seu livro lhes permite sempre abrir e abordar uma gama formidável de temas e problemas, ao mesmo tempo que nem sempre thes permite dar vazão à sua veia teórica na medida necessária. Essa constrição formal da reflexão teórica impõe a Capitalismo em debate três importantes 
limitações: a primeira diz respeito à relação da teorização que as autoras oferecem com a economia política e, em particular, com a teorização de Karl Marx; a segunda, à clarificação da religião nas suas (perigosas) relações com o capitalismo; e a terceira, à elucidação dos supostos populismos hodiernos. Tais limitações podem ser formuladas através das seguintes questões, que, no livro, ficam intocadas:

Que traços fundamentais teria uma nova economia política que levasse a sério seja a concepção expandida de capitalismo de Fraser, seja a concepção alargada de economia de Jaeggi? Permaneceriam sustentáveis as bases do edifício teórico da crítica marxiana da economia política ante as novas, mais profundas e mais complexas concepções de trabalho, natureza, acumulação, contradição, crise, classe, luta de classes, democracia, sociedade e socialismo de Fraser? Como precisamente essas concepções de Fraser impactam as centrais conceituações marxianas de valor e mais-valor?

Que lugar a religião ocupa na sociedade capitalista? Ela chegaria a constituir, para Fraser, uma esfera social própria com a qual a economia, assim como com a reprodução social, a política e a ecologia, manteria uma relação de separação, dependência e denegação; ou, para Jaeggi, uma forma de vida de escopo limitado, mas de forte resistência, sob a modernidade como uma abrangente forma de vida secularizada? Ou se circunscreveria ela a um resíduo de eticidade pré-moderna que, embora essencialmente incompatível com a secularidade moderna, pode ser e, de fato, é reaproveitado na sociedade capitalista para fins hegemônicos (diria Fraser, quiçá) ou ideológicos (talvez dissesse Jaeggi)?

E que é populismo? Os atuais presidentes estadunidense e brasileiro (Donald Trump e Jair Bolsonaro), por exemplo, são mesmo populistas? Não seria mais adequado caracterizá-los como autoritários ou até fascistas? O que diferiria, hoje, o populismo do autoritarismo e do fascismo?

Sem embargo dessas limitações gerais, Capitalismo em debate tem como virtude principal a de ser um livro tempestivo, um livro que liga estreita e profundamente a reflexão teórica ao seu contexto social, um livro que cabe ler justamente em meio à "turbulência que se aprofunda ao nosso redor" (p. 9). Ao final da leitura, permanecem ressoando as palavras de Fraser: "a crise não será resolvida com o ajuste desta nem daquela política. 0 caminho para a sua resolução só pode ser o da transformação estrutural profunda dessa ordem social"; palavras, aliás, reverberadas por Jaeggi: "sem um projeto emancipatório para além das alternativas às quais as pessoas parecem presas agora, as coisas podem ficar feias” (pp. 241-242).

\section{Referências}

Fraser, N. (2013). Fortunes of feminism: from state-managed capitalism to neoliberal crisis. London; New York: Verso. 
Fraser, N. (2014). Behind Marx's hidden abode: for an expanded conception of capitalism. New Left Review, 86, pp.141-159.

Fraser, N. (2016). Contradictions of capital and care. New Left Review, 100, pp.99117.

Fraser, N. (2018a). Crise de legitimação? Sobre as contradições políticas do capitalismo financeirizado. Tradução de José Ivan Rodrigues de Sousa Filho. Cadernos de Filosofia Alemã: Crítica e Modernidade, 23 (2), pp.153-188.

Fraser, N. (2018b). Do neoliberalismo progressista a Trump - e além. Tradução de Paulo S. C. Neves. Política \& Sociedade: Revista de Sociologia Política, 17 (40), pp.43-64.

Fraser, N. (2018c). From exploitation to expropriation: historic geographies of racialized capitalism. Economic Geographic, 94 (1), pp.1-17.

Fraser, N. (2020). What should socialism mean in the twenty-first century? Socialist Register, 56, pp.282-294.

Fraser, N., \& Honneth, A. (2003). Redistribution or recognition? A politicalphilosophical exchange. Translated by Joel Golb, James Ingram, and Christiane Wilke. London; New York: Verso.

Jaeggi, R. (2008). Repensando a ideologia. Tradução de Emil Sobottka e Giovani Saavedra. Civitas, 8 (1), pp.137-165.

Jaeggi, R. (2014). Alienation. Translated by Frederick Neuhouser and Alan E. Smith. New York: Columbia University Press.

Jaeggi, R. (2015). O que há (se de fato há algo) de errado com o capitalismo? Três vias de crítica do capitalismo. Tradução de Nathalie Bressiani. Cadernos de Filosofia Alemã: Crítica e Modernidade, 20 (2), pp.13-36.

Jaeggi, R. (2017). Pathologies of work. Women's Studies Quarterly, 45 (3-4), pp.5976.

Jaeggi, R. (2018a). Critique of forms of life. Translated by Ciaran Cronin. Cambridge; London: The Belknap Press of Harvard University Press.

Jaeggi, R. (2018b). Um conceito amplo de economia: economia como prática social e a crítica ao capitalismo. Tradução de Alessandro Pinzani. Civitas, 18 (3), pp.503522.

Recebido em: 03.06.2020

Aceito em: 25.06.2020

Esta obra está licenciada com uma Licença Creative Commons Atribuição-NãoComercial-

-Compartilhalgual 4.0 Internacional.

https://creativecommons.org/licenses/by-nc-sa/4.0/

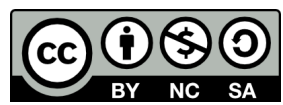

